\section{ISLL}

Recibido:

Septiembre 2013

Publicado:

Enero 2014

ISSN: $2340-8685$

$\mathbf{N}^{\circ}$ DEPÓSITO LEGAL:

MA 1949-2013

Pág 49 a la 56

Palabras clave

Intertextualidad, Saramago, Monterroso, Niveles de lectura

\section{Keywords}

Intertextuality, Saramago, Monterroso, Levels of reading

\title{
El reflejo de la lectura de Monterroso en El Hombre Duplicado
}

\author{
Raquel López Ruano
}

IES “Rafael Reyes" de Cartaya

Elena Jiménez Pérez

Universidad de Granada

\section{Resumen}

En la novela El hombre duplicado, Saramago intertextualiza el brevísimo relato de El dinosaurio de Augusto Monterroso y hace una peculiar interpretación del mismo.

La genialidad de Saramago consiste en desplegar una doble complicidad, hacia Monterroso y hacia el lector.

El hombre duplicado admite varios niveles de lectura y puede llegar a distintos tipos de lectores porque en esta obra se entrecruzan continuamente lo culto y lo popular del pensamiento y del lenguaje.

\begin{abstract}
Summary
In the novel El hombre duplicado, Saramago intertextualiza the brief story of Augusto Monterroso dinosaur and makes a peculiar interpretation of the same. The genius of Saramago consists of deploying a double complicity, towards Monterroso and towards the reader. El hombre duplicado admits several levels of reading and can come to different types of readers because in this work there interbreed constant the educated thing and the popular of the thought and of the language.
\end{abstract}




\section{Introducción}

En la novela El hombre duplicado, que se publicó por primera vez en 2002, apenas un año antes de que muriera Augusto Monterroso (el 7 de febrero de 2003), José Saramago intertextualiza el brevísimo relato de El dinosaurio como reconocimiento literario a este indiscutible innovador del género del microrrelato.

La intertextualidad que realiza Saramago del texto de Monterroso no se basa en una evocación explícita y completamente literal sino que es más bien recreada e implícita, por lo que exige "que sea el lector quien localice la referencia" (Adsuar, 2008: 1).

Con este trabajo se pretende demostrar cómo escritor y lector son figuras indisolublemente unidas y cómo el universo personal de un creador, en este caso concreto José Saramago, está configurado por su experiencia lectora.

La "huella" de autores consagrados es una técnica que goza de una larguísima tradición en literatura y podría englobarse en el amplio epígrafe de la imitación. La imitación debe entendederse "como una reproducción, que puede ser refundición, o bien una nueva configuración” (Curtius, 1955: 570). Se puede hablar, incluso, de reconstrucción que "consiste en deshacer, en desmontar algo que se ha creado o elaborado pero no con la intención de destruirlo" (Andrés, 2008: 97).

Entre los muchos juegos metaliterarios que Saramago establece en su novela $E l$ hombre duplicado, destaca su peculiar interpretación del famoso microrrelato de Monterroso «Cuando despertó, el dinosaurio todavía estaba allí» (Monterroso, 1998: 77). Además, la presencia de la poética de Monterroso es tan fuerte a lo largo de esta obra que podemos captar la admiración y el respeto que Saramago sentía por dicho autor, hasta el punto de que se podría decir que es uno de los ejes que configura la obra.

El microrrelato de El dinosaurio, por su carácter innovador, por su brevedad y por lo sorprendente de su principio y su final, es uno de los textos de la literatura en Lengua española más recordados, estudiados, citados, glosados, parodiados e incluso criticados. Pero no vamos a hablar aquí de la originalidad de Monterroso, que por descontado la tiene, sino de la interpretación que Saramago hizo de este texto en El hombre duplicado.

La genialidad de Saramago consiste en desplegar una doble complicidad, hacia Monterroso y hacia el lector, y la sostiene moviéndose constantemente entre lo popular y lo literario. Saramago inserta el microrrelato de Monterroso, distribuyéndolo en varios pasajes, dentro de una novela que se centra en el problema de la identidad del ser humano, y hace que encaje tanto en el hilo argumental como en la situación y en el carácter de los personajes. Para ello no glosa el cuento de Monterroso sino que lo contextualiza, lo adapta, lo reinterpreta. De esta manera ayuda al autor a hacer más comprensible su mensaje, se convierte en su cómplice.

\section{La interpretación de Saramago}

Saramago no quiere repetir las palabras de Monterroso "Cuando despertó, el dinosaurio todavía estaba allí" por evocación explícita, como si fuera un erudito, por eso deja que caigan de los labios de un personaje sencillo, la anciana madre del protagonista, Carolina, 
un personaje hecho de literatura y vivencias: por una parte es "una asidua y fervorosa lectora de novelas" (Saramago, 2003: 154), y nos la imaginamos como una lectora poco erudita, ávida de novelas sentimentales o de folletín; y por otra parte, conoce a la perfección el alma humana, como ella misma manifiesta en una conversación con su hijo, el solitario Tertuliano Máximo Afonso: "Sabía que tenías dotes de psicóloga, pero no que llegaran a tanto, De psicóloga no sé nada, nunca he estudiado ni una línea, pero de personas creo saber algo" (Saramago, 2003: 156).

Por el tipo de lectura que hace, si aplicamos la intertextualidad, nos recuerda a los personajes femeninos de tantas novelas decimonónicas, como, por poner un ejemplo, la sentimental Ana Ozores de La Regenta.

Por sus palabras, sabemos de sus artes de tercera y de su gran psicología popular, lo que nos recuerda, aplicando de nuevo el principio de intertextualidad, a nuestro entrañable personaje de Celestina. Saramago consigue mediante un sencillo collage que Carolina mencione alterado el mensaje de Monterroso y lo convierta en material popular, como si fuera una sentencia propia de la fraseología, con su correspondiente carga de filosofía elemental: "Para que ella todavía esté cuando tú despiertes" (Saramago, 2003: 297). Y "consigue, mediante el uso del proberbio, una gran efectividad en la comunicación" (Postigo, 2001: 272).

En este pasaje el verbo despertar tiene el mismo valor que emplea Manrique en su famosa copla "Recuerde el alma dormida,/avive el seso e despierte/contemplando" y el mismo sentido figurado con que se emplea en el uso popular del lenguaje: 'darse cuenta de algo, tomar consciencia'. Con el significado de despertar aparece en la $4^{\mathrm{a}}$ acepción del Diccionario de la RAE: “4. intr. Ast., León, Arg., Col., Ec., Méx. y R. Dom. despertar" (RAE, 2001, $22^{\mathrm{a}}$ ed.). La elección por parte de Saramago de la acepción arcaica de esta palabra es deliberada por su carga filosófica y simbólica, que se mantiene en el lenguaje popular de las sentencias.

En su afán lúdico, Saramago pretende involucrar a un lector amplio a través de una técnica a la que este está muy habituado, gracias al mundo de la publicidad, y que consiste en variar alguna palabra de una frase hecha. Es lo que Postigo llama "falsos proberbios que imitan la estructura de los enunciados sentenciosos" (Postigo, 2001: 276). En este caso, el proberbio alterado es el texto de Monterroso: "Para que ella todavía esté cuando tú despiertes" (Saramago, 2003: 297). El lector sonreirá al darse cuenta de la broma. Saramago le ha hecho un guiño para que adopte una posición activa y reconozca ahora al "dinosaurio", que ha sido reemplazado por una mujer: María Paz. De nuevo las palabras de la madre, esta vez las recuerda Tertuliano al escuchar en el contestador el mensaje de María Paz: "le había venido a la memoria lo que la madre le dijo, Ojalá ella todavía esté cuando tú despiertes, Máximo" (Saramago, 2003: 306).

Y salen otra vez en una conversación telefónica entre Tertuliano y María Paz: "Quieres saber lo que mi madre me dijo ayer en un momento en que hablábamos de ti, Qué, Ojalá ella todavía esté cuando tú despiertes [...], Despertaste y yo todavía estaba aquí" (Saramago, 2003: 308).

Saramago ha resuelto una sencilla ecuación en la que el dinosaurio cobra un valor concreto y, por otra parte, ha contribuido a fijar en la memoria colectiva, como si fuera una sentencia o frase hecha, el relato. Probablemente muchos lectores no recuerden el nombre del autor del microrrelato «cuando despertó el dinosaurio todavía estaba allí» pero recordarán el 
texto e, incluso, habrán aprendido a insertarlo en un contexto, a darle un principio y un final o, si llega el caso, a cambiar el dinosaurio por otro sujeto gramatical.

\section{El homenaje a Monterroso}

La presencia de Monterroso está detrás de las palabras de Saramago (no olvidemos la complicidad de la que hace unas líneas hemos hablado) y este, que ha contribuido a actualizar y popularizar las palabras de aquel, parece que ha seguido varios puntos de su famoso «decálogo del escritor»: un interesante documento, inserto en la segunda parte de la primera y única novela del guatemalteco, Lo demás es silencio (publicada por primera vez en 1978), que pretende ser una elaboración del personaje apócrifo Eduardo Torres, un escritor provinciano que protagoniza una autobiografía ficticia de Monterroso:

Saramago no toma este decálogo al pie de la letra, en concreto se basa en los puntos segundo, tercero, décimo y undécimo. 138):

Reproducimos a continuación el «decálogo del escritor»(Monterroso, 1982: 136-

Primero.

"Cuando tengas algo que decir, dilo; cuando no, también. Escribe siempre”.

Segundo.

"No escribas nunca para tus contemporáneos, ni mucho menos, como hacen tantos, para tus antepasados. Hazlo para la posteridad, en la cual sin duda serás famoso, pues es bien sabido que la posteridad siempre hace justicia".

\section{Tercero.} escrito»".

"En ninguna circunstancia olvides el célebre dictum: «En literatura no hay nada

Cuarto.

"Lo que puedas decir con cien palabras dilo con cien palabras; lo que con una, con una. No emplees nunca el término medio; así, jamás escribas nada con cincuenta palabras".

Quinto.

"Aunque no lo parezca, escribir es un arte; ser escritor es ser un artista, como el artista del trapecio, o el luchador por antonomasia, que es el que lucha con el lenguaje; para esta lucha ejercítate de día y de noche".

Sexto.

"Aprovecha todas las desventajas, como el insomnio, la prisión o la pobreza; el primero hizo a Baudelaire, la segunda a Pellico y la tercera a todos tus amigos escritores; evita, pues, dormir como Homero, la vida tranquila de un Byron o ganar tanto como Bloy”. 


\section{Séptimo.}

"No persigas el éxito. El éxito acabó con Cervantes, tan buen novelista hasta $E l$ Quijote. Aunque el éxito es siempre inevitable, procúrate un buen fracaso de vez en cuando para que tus amigos se entristezcan".

\section{Octavo.}

"Fórmate un público inteligente, que se consigue más entre los ricos y los poderosos. De esta manera no te faltarán ni la comprensión ni el estímulo, que emana de estas dos únicas fuentes".

\section{Noveno.}

"Cree en ti, pero no tanto; duda de ti, pero no tanto. Cuando sientas duda, cree; cuando creas, duda. En esto estriba la única verdadera sabiduría que puede acompañar a un escritor".

\section{Décimo.}

"Trata de decir las cosas de manera que el lector sienta siempre que en el fondo es tanto o más inteligente que tú. De vez en cuando procura que efectivamente lo sea; pero para lograr eso tendrás que ser más inteligente que él”.

Undécimo.

"No olvides los sentimientos de los lectores. Por lo general es lo mejor que tienen; no como tú, que careces de ellos, pues de otro modo no intentarías meterte en este oficio".

\section{Duodécimo.}

"Otra vez el lector. Entre mejor escribas más lectores tendrás; mientras les des obras cada vez más refinadas, un número cada vez mayor apetecerá tus creaciones; si escribes cosas para el montón nunca serás popular y nadie tratará de tocarte el saco en la calle, ni te señalará con el dedo en el supermercado".

Como se puede apreciar, el lector tiene una presencia importante en este decálogo que se supone es de escritor.

Aunque Monterroso le da a cualquier escritor la opción de descartar dos de estos enunciados y quedarse con diez, Saramago aplica en El hombre duplicado cuatro de estos principios; los seis restantes, tienen que ver, en general, con la tarea de escribir:

El segundo: "No escribas nunca para tus contemporáneos, ni mucho menos, como hacen tantos, para tus antepasados. Hazlo para la posteridad, en la cual sin duda serás famoso, pues es bien sabido que la posteridad siempre hace justicia".

Saramago, a través de su obra y mediante el recurso de la metaliteratura, catapulta a "la posteridad" su propia interpretación del cuento de Monterroso. Y, a la vez, gracias a la crítica literaria implícita en su obra, como hiciera Cervantes en su día en el escrutinio de $E l$ Quijote, el novelista portugués lanza a la posteridad al autor que tanto admira. 
El tercero: "En ninguna circunstancia olvides el célebre dictum: «En literatura no hay nada escrito»".

Este punto se puede interpretar de dos formas complementarias:

1) Saramago está transformando el texto de Monterroso con su permiso porque se acoge a sus propias palabras, no trancribiéndolo al pie de la letra.

2) Saramago convierte el texto de Monterroso, al transformarlo y eludir el nombre del autor, en material fraseológico, en frase popular. Este recurso no es nuevo, pues aparece ampliamente en la literatura medieval: en la épica, en el romancero, en los cuentos, etc. Sirvan como ejemplo las palabras de la madre de Boabdil cuando tienen que abandonar Granada: "Lloras como una mujer / lo que no has sabido defender como un hombre". Estas palabras de un romance fronterizo se han convertido hoy en materia fraselógica del acervo cultural español.

El décimo: "Trata de decir las cosas de manera que el lector sienta siempre que en el fondo es tanto o más inteligente que tú. De vez en cuando procura que efectivamente lo sea; pero para lograr eso tendrás que ser más inteligente que él”.

Está muy claro que el lector va a captar inmediatamente el juego intelectual que Saramago le propone al incorporar a su novela un ingrediente literario tan valioso: la interpretación de un cuento archiconocido, que ya es un clásico de nuestra Literatura. Pero Saramago va más lejos aún: al mismo tiempo considera muy inteligente a Monterroso por ser el autor de esta brillante la idea.

El undécimo: "No olvides los sentimientos de los lectores. Por lo general es lo mejor que tienen; no como tú, que careces de ellos, pues de otro modo no intentarías meterte en este oficio".

En este punto la defensa de la dignidad del ser humano que desprenden los escritos de Saramago con ese gusto suyo por personajes corrientes y cotidianos serán el arma más poderosa con la que llegar al sentido común de los lectores, lo que le devolverá su simpatía en el sentido etimológico de "sentir contigo".

En El hombre duplicado, su protagonista, Tertuliano Máximo Afonso, aparece como un personaje trazado con rasgos literarios intertextuales, como el Augusto Pérez de Niebla con su aburrida cotidianeidad. Por eso Saramago construye su mundo a través de un juego metaliterario, con numerosas referencias, encubiertas o no, a numerosas obras y personajes literarios: desde la mención expresa de Casandra a la sutil evocación de Celestina. En este continuo ir y venir a la tradición literaria, trae a colación el relato mínimo de Monterroso y lo interpreta libremente, con descaro pero, a la vez, con un profundo afecto y con mucho respeto hacia Monterroso, lo que demuestra que Saramago es un buen lector y las referencias de su obra dan prueba de su riqueza lectora. "Las alusiones intertextuales son una constante del estilo saramaguiano y, desde esta perspectiva de la obra, como mosaico de citas, son numerosos los análisis que se han realizado" (Postigo, 2001: 270). 
El hombre duplicado propone un juego intelectual al más alto nivel literario, en el que el lector, que ha de tener cierto entrenamiento, deberá agudizar el ingenio al máximo, porque la magia que teje Saramago no es fácil y se escapa de una lógica simple, para leer entre líneas y captar las más variadas referencias literarias. La comunicación total entre autor y lector se basa aquí en una entropía similar a la que se dio en ciertas épocas altamente impregnadas de cultura literaria como nuestro siglo de Oro o la época del 27.

Pero, por otra parte, Saramago, que es un autor con una esencia muy humana, no quiere llegar solamente a un lector culto, sino a todos, y para lograr que su mensaje pueda ser interpretado por lectores no "tan leídos" transforma lo literario en palabras sencillas con fórmulas populares que nos recuerdan a los refranes o sentencias: "Ojalá ella todavía esté cuando tú despiertes [...] Despertaste y yo todavía estaba aquí”. Es todo un acierto esta invocación que no requiere haber leído el original para interpretar el sentido del texto y, en ese sentido, no cierra la puerta a que lectores que por un casual no conozcan el microrrelato no disfruten de todos los matices.

El hombre duplicado admite varios niveles de lectura y puede llegar a distintos tipos de lectores porque en esta obra se entrecruzan continuamente lo culto y lo popular del pensamiento y del lenguaje. La entropía o cantidad de información transmitida y recibida se presta a distintas tesituras o grados de interpretación. 


\section{Bibliografía}

- Adsuar Fernández, Ma D. (2008). La intertextualidad, (E)vocación de mundos posibles, Cartaphilus (Revista de Investigación y Crítica estética), 4, 1-8.

- Andrés Sebastià, M $M^{a}$ P. (2008). Jorge Luis Borges y las Coplas manriqueñas: referencias intertextuales en el aula de E/LE, Actas del II Congreso Internacional de Lengua y Literatura y Cultura de E/LE: Teoría y Práctica docente. Onda: JMC, 95108.

- Curtius, E. R. (1955). Literatura europea y Edad Media Latina. Madrid: Fondo de Cultura Económica.

- Monterroso, A. (1982). Lo demás es silencio. Madrid: Cátedra.

- Monterroso, A. (1998). Obras completas (y otros cuentos). Barcelona: Editorial Anagrama.

- Postigo Aldeamil, Ma J. (2001). José Saramago y los proverbios, Revista de Filología Románica, 2, 267-299.

- RAE (2001). Diccionario de la Lengua española, 22ª ed., Madrid: Espasa-Calpe.

- Saramago, J. (2003). El hombre duplicado, Barcelona: Círculo de lectores. 